\title{
Diabetes and Endocrinology
}

\section{From Bench to Bedside as well as to "The Society": An Open Discussion is Critical for Progress of Medicine}

\author{
Yoshifumi Saisho, MD, PhD* \\ Department of Internal Medicine, Keio University School of Medicine, Tokyo, Japan
}

am pleased to announce the launch of this new journal "Diabetes and Endocrinology" with excellent editorial board members as a new plat-

form for superb scientific and medical reports. Our purpose is to provide an opportunity to discuss among the researchers for a better understanding of diabetes and endocrinology. Open discussion is critical for the progress of medicine. We accept a broad range of manuscripts including original article, review, editorial, commentary, opinion and perspective regarding any aspects of diabetes and endocrinology, both basic as well as clinical studies.

Diabetes and endocrine disorders encompass a broad range of diseases. Among them, diabetes poses a serious threat to the world. Despite the extermination statement by the United Nations in 2006, the number of people with diabetes continues to increase. The people with diabetes suffer from various problems, including microvascular (retinopathy, nephropathy and neuropathy) and cardiovascular complications. Recent studies have also revealed the increased risks of cancer, bone fracture, cognitive dysfunction and periodontal disease in the people with diabetes. Therefore, a multifaceted approach from wide range of experts including, but not limited to, diabetologists / endocrinologists, cardiologists, ophthalmologists, neurologists, psychiatrists, dentists, nurses, dietitians, pharmacists, biologists, chemists and engineers is needed to explore the pathophysiology of diabetes, and to establish new approach for the treatment of these complications. The current pandemic of diabetes in the world is also closely related to changes in our society. Thus, we need to discuss not only the medical aspects but also the social, environmental and cultural aspects as the pathogenesis of diabetes. Other endocrine disorders such as thyroid diseases, adrenal diseases and pituitary diseases also need a multifaceted approach from different fields of expertise.

*Correspondence: Yoshifumi Saisho, MD, PhD

Department of Internal Medicine, Keio University School of Medicine, Tokyo, 160-8582, Japan.

E-mail: ysaisho@keio.jp

Received: July 25, 2017; Accepted: July 28, 2017; Published: July 30, 2017

Diabetes and Endocrinology. 2017;1(1):1

DOI: 10.24983/scitemed.de.2017.00020

Copyright (c) 2017 The Author. This is an open-access article distributed under the terms of the Creative Commons Attribution 4.0 International License (CC$\mathrm{BY})$.
Our final goal is to seek better outcomes for the patients. Our major goals include establishing new treatment or management, and also prevention. For prevention, we need to speak to our colleague researchers and also to the general population, or "the society". I believe that this open journal can also provide such an opportunity to update our current knowledge to the general population.

All the readers are welcome to submit their superb scientific and medical manuscripts. The new journey just starts!

Yoshifumi Saisho, MD, PhD

Editor-in-Chief

Diabetes and Endocrinology
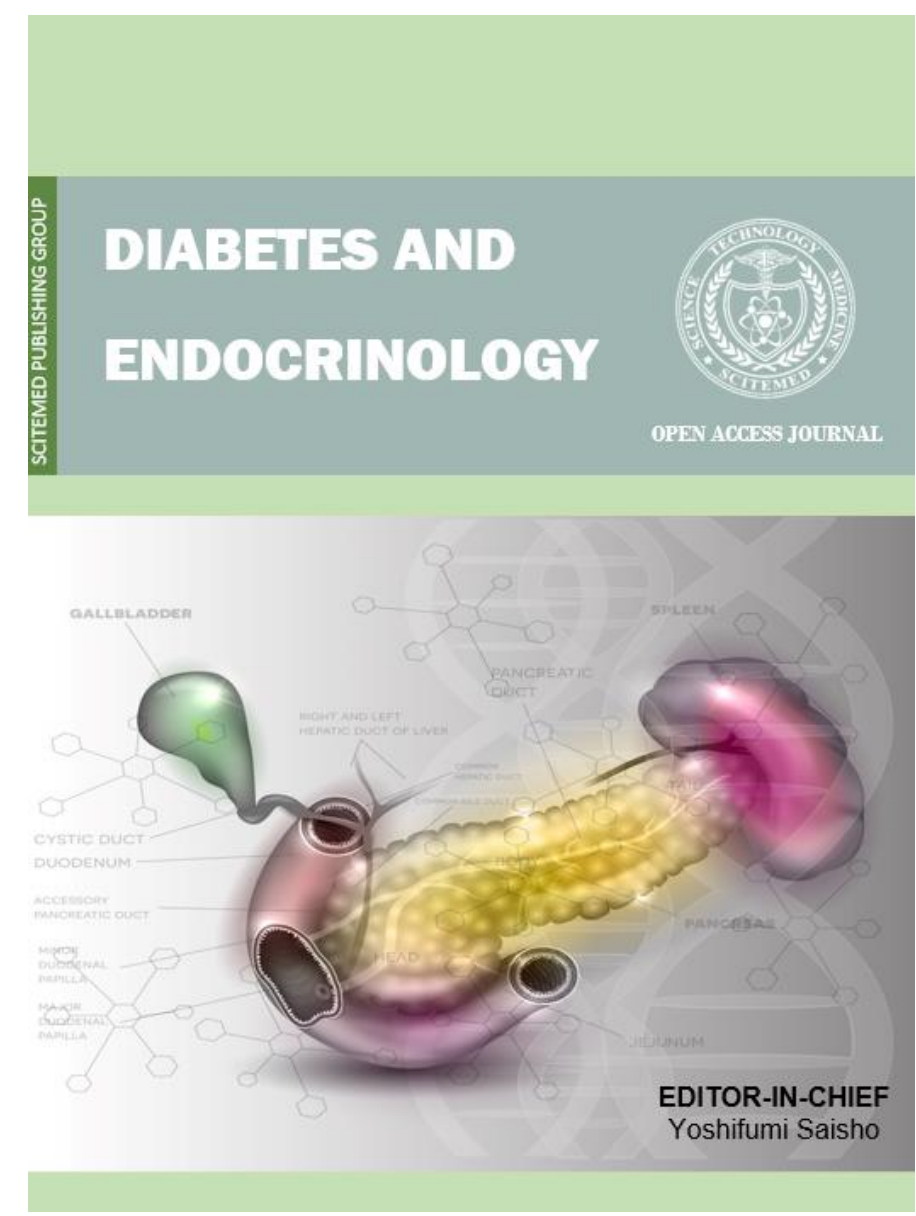